\title{
Determination of the Optimal Design of a Thermal Panel of an Autonomous Residential Module by Calculating Temperature Fields
}

\author{
V.D. Makarishev, G.A. Savenko, S.M. Usikov \\ National Research Moscow State University of Civil Engineering, 26, Yaroslavskoye Shosse, Moscow, 129337, \\ Russia
}

\begin{abstract}
The article is devoted to the study of the modern application of heating systems in outdoor enclosures to ensure optimal temperature parameters in autonomous residential modules. To solve this problem, a numerical method with application of a grid and creation of a mathematical model of the temperature distribution in the thickness of the fence was used. Some ways of regulating the operation of this system were also considered and calculated. This material can be used in further research on the design and development of autonomous residential modules, as well as in the development of materials and techniques for laying heating systems in the thickness of fences.
\end{abstract}

Key words: heating system, mathematical model, autonomous residential containers.

\section{INTRODUCTION}

In order to create workplaces at construction sites or temporary research sites rapidly autonomous residential module are currently applied. In practice, these buildings are containers with interior decoration, where work places, or recreation areas are located [1-6]. Special microclimate systems should be provided for comfortable human presence in these containers.

If the installation of containers is planned in warm regions in summer, it is sufficient to provide an air ventilation system that ensures the quality of air environment. However, if the installation of containers is planned in the cold season, or in the regions of the far North, then it is necessary to provide a heating system.

In the case of a heating system, the walls, floor and ceiling of insulated containers are made of a layer of expanded polystyrene between the outer and inner surface of the container, usually made of rolled steel. If necessary, an additional decorative layer is installed on the walls inside the container.

Maintenance of the temperature in the container in this case is carried out by installing an electric convector that warms the room air. This method has a number of disadvantages in terms of comfort [7], in particular, the inner surface of the barrier structure will be cold, which will negatively affect the well-being of people in the container.

An autonomous residential module equipped with a heating system for heating the entire floor area, sized 2200x6000 mm, is taken as an example of the object of research. Outdoor conditions are accepted as $-40{ }^{\circ} \mathrm{C}$, and the required room temperature is $18{ }^{\circ} \mathrm{C}$. The proposed panel design is shown in Figure 1.

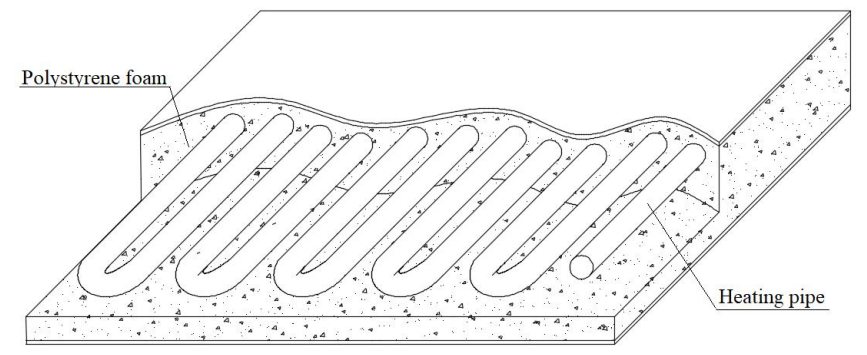

Figure 1: The proposed panel design

When considering panel, two important questions arise: what the minimum temperature formed on the inner surface of the barrier structure is and what losses should be taken into account when loading the heating system. The maximum floor surface temperature is limited by comfort conditions [8]. In this case, we accept a limit of no more than $26^{\circ} \mathrm{C}$.

\section{METHODOLOGY}

To solve this problem, on the basis of the energy equation, a mathematical model of the temperature distribution over the thickness of the panel is formed:

$\frac{\partial t}{\partial \tau}=a\left(\frac{\partial^{2} t}{\partial x^{2}}+\frac{\partial^{2} t}{\partial y^{2}}+\frac{\partial^{2} t}{\partial z^{2}}\right)+\frac{q_{v}}{c \rho}+\left(U_{x} \frac{\partial t}{\partial x}+U_{y} \frac{\partial t}{\partial y}+U_{z} \frac{\partial t}{\partial z}\right)$,

$t$ - temperature in the panel thickness, ${ }^{\circ} \mathrm{C} ; \tau$-time, c; $a-$ diffusivity, $\mathrm{m} / \mathrm{s}^{2} ; q_{v}-$ volumetric heat dissipation, $\mathrm{W} / \mathrm{m}^{3} ; c-$ specific mass heat capacity, $\mathrm{J} /\left(\mathrm{kg} \square{ }^{\circ} \mathrm{C}\right) ; \rho-$ density, $\mathrm{kg} / \mathrm{m}^{3} ; U_{x}$ - travel speed, $\mathrm{m} / \mathrm{s}$.

In this case, the problem is considered in stationary conditions $-\frac{\partial t}{\partial \tau}=0$, volumetric heat release does not occur, since there are no internal chemical reactions $-\frac{q_{v}}{c \rho}=0$, and 
also the panel material is stationary $U_{x} \frac{\partial t}{\partial x}+U_{y} \frac{\partial t}{\partial y}+U_{z} \frac{\partial t}{\partial z}=0$.

Therefore, the problem is to solve a three-dimensional temperature field:

$$
\frac{\partial^{2} t}{\partial x^{2}}+\frac{\partial^{2} t}{\partial y^{2}}+\frac{\partial^{2} t}{\partial z^{2}}=0
$$

The boundary conditions of the problem will be [8]:

1. Boundary conditions of the third kind - the coefficient of heat transfer on the inner surface of the floor is set $\alpha_{i n}, \mathrm{~W} /\left(\mathrm{m}^{2} \square{ }^{\circ} \mathrm{C}\right)$, in this case 8.7 $\mathrm{W} /\left(\mathrm{m}^{2} \square{ }^{\circ} \mathrm{C}\right), \mathrm{v} t_{i n},{ }^{\circ} \mathrm{C}$, in our case $18{ }^{\circ} \mathrm{C}$.

2. Boundary conditions of the third kind - the coefficient of heat transfer on the external surface of the floor is set $\alpha_{\text {out }}, \mathrm{W} /\left(\mathrm{m}^{2} \square{ }^{\circ} \mathrm{C}\right)$, in our case 23 $\mathrm{W} /\left(\mathrm{m}^{2} \square{ }^{\circ} \mathrm{C}\right)$, and the outside air temperature $t_{i n}$, ${ }^{\circ} \mathrm{C}$, in our case $-40{ }^{\circ} \mathrm{C}$.

3. Boundary conditions of the first kind are the temperature on the surface of the heating system pipe. In our case, the temperature is set by a law that takes into account the cooling of water along the flow of the coolant:

$$
\frac{\partial t}{\partial l}=0.5,
$$

that is, for each meter of the pipe, the coolant is cooled by 0.5 ${ }^{\circ} \mathrm{C}$. This is a very unreliable law for describing a decrease in the temperature of the coolant, which should be clarified further, depending on the panel design and the temperature of the coolant. Boundary conditions of the third kind can be applied in equation (2) by changing the temperature on the wall surface. To do this, we will use the Fourier equation (4) and the Newton-Richman equation (5):

$$
\begin{array}{r}
q=-\lambda\left(\frac{\partial t}{\partial x}+\frac{\partial t}{\partial y}+\frac{\partial t}{\partial z}\right) \\
q=\alpha_{\text {out }}\left(t-t_{\text {out }}\right)
\end{array}
$$

For a point on the outer surface of the panel, the heat transfer process propagates only in one direction - down, or if the Cartesian coordinate system is applied along the $\mathrm{z}$ axis. Then:

$$
q_{z}=-\lambda\left(\frac{\partial t}{\partial z}\right)=-\alpha_{\text {out }}\left(t-t_{\text {out }}\right) .
$$

Therefore, the total heat flow at a given point can be expressed as:

$$
q=-\lambda\left(\frac{\partial t}{\partial x}+\frac{\partial t}{\partial y}\right)-\alpha_{\text {out }}\left(t-t_{\text {out }}\right) \text {. }
$$

It is known that the change in enthalpy I, J/kg, in the volume of material $\mathrm{V}, \mathrm{m} 3$, is equal to the total heat flow through the surface of this volume $\mathrm{S}, \mathrm{m} 2$ :

$$
\int_{V} \frac{d(c \rho t)}{d \tau} d V=\int_{S} q d S .
$$

Using the Ostrogradsky-Gauss theorem and substituting equation (6), we obtain:

$$
c \rho \frac{\partial t}{\partial \tau}=\nabla \cdot\left(\lambda\left(\frac{\partial t}{\partial x}+\frac{\partial t}{\partial y}\right)+\alpha_{\text {out }}\left(t-t_{\text {out }}\right)\right) .
$$

After the transformations, we get:

$$
c \rho \frac{\partial t}{\partial \tau}=\lambda\left(\frac{\partial^{2} t}{\partial x^{2}}+\frac{\partial^{2} t}{\partial y^{2}}\right)+\frac{\partial}{\partial z^{2}} \alpha_{\text {out }}\left(t-t_{\text {out }}\right) \text {. }
$$

Since the problem is solved for a stationary temperature field, then:

$$
\lambda\left(\frac{\partial^{2} t}{\partial x^{2}}+\frac{\partial^{2} t}{\partial y^{2}}\right)+\frac{\partial}{\partial z^{2}} \alpha_{\text {out }}\left(t-t_{\text {out }}\right)=0 .
$$

For the inner surface of the floor, equation (10) will take the form:

$$
\lambda\left(\frac{\partial^{2} t}{\partial x^{2}}+\frac{\partial^{2} t}{\partial y^{2}}\right)+\frac{\partial}{\partial z^{2}} \alpha_{i n}\left(t-t_{i n}\right)=0 .
$$

Based on equations (2), (10) and (11), as well as boundary conditions, a mathematical model of the panel under consideration was constructed.

This system of equations was solved by the finite difference method [9]. First of all, the calculation grid was built on the panel, the design of which is shown in figure 2. In the first case, the pipe was deepened at $\mathrm{h}=20 \mathrm{~mm}$ from the floor surface. In this case, the grid step was taken as: $\Delta x=10 \mathrm{~mm} ; \Delta y=10 \mathrm{~mm} ; \Delta z=10 \mathrm{~mm}$.

Grid overlay are shown in Figure 3.

It is worth noting that since the wall of the pipe does not fall on the design points, it was assumed that the nearest points of the design grid to the pipe have a surface temperature of the grid. In figure 3, this is shown by the highlighted points near the pipe.

The source for the calculation of the first variant of the structural design:

- the water temperature at the inlet of the panel $95^{\circ} \mathrm{C}$;

- the pipe is buried in the $h=20 \mathrm{~mm}$;

- thermal conductivity of the material $\lambda=0,032 \mathrm{~W} /\left(\mathrm{m} \square{ }^{\circ} \mathrm{C}\right)$. 


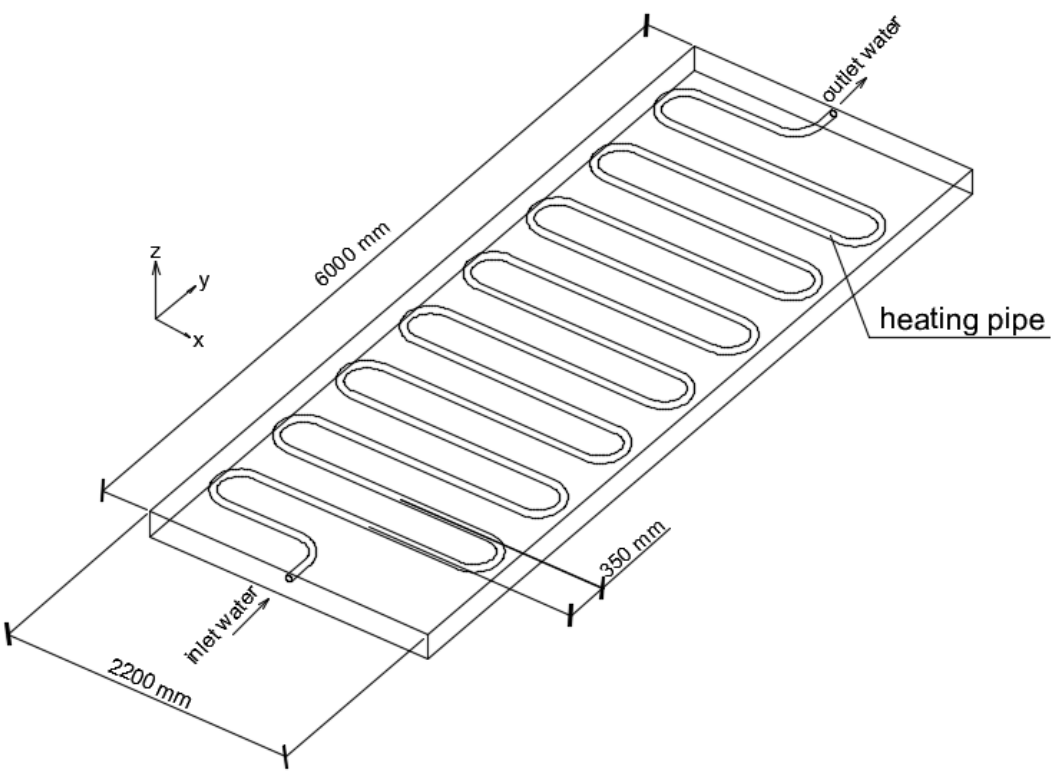

Figure 2: Panel dimensions and axis

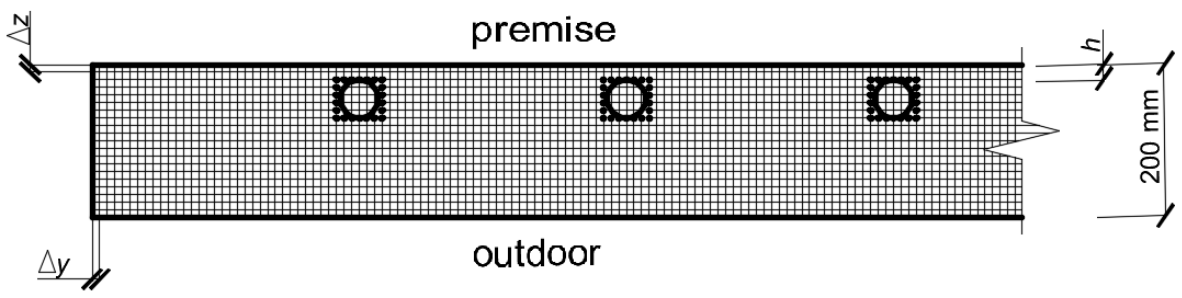

Figure 3: Grid overlay and heat balance components

Based on the calculation results, the temperature distribution on the floor surface is obtained (Fig. 4).
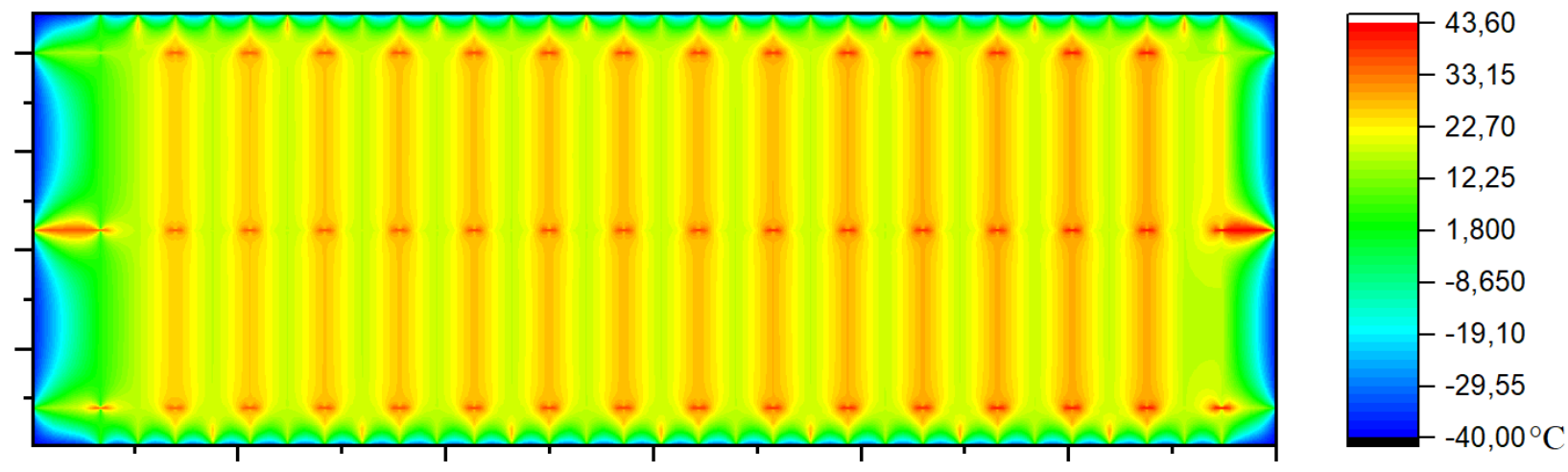

Figure 4: Temperature map. First version panel

The maximum temperature on the panel surface was up to $43.6{ }^{\circ} \mathrm{C}$, which is unacceptable for comfort requirements. Moreover, as you can see from the graph, there are quite a lot of such overheated zones.

In the next version, the heating system pipe was buried $\mathrm{h}=50$ $\mathrm{mm}$ from the floor level, and the coolant temperature at the entrance to the panel was $95{ }^{\circ} \mathrm{C}$. Based on the simulation results, a temperature map of the panel was obtained (Fig. 5). 

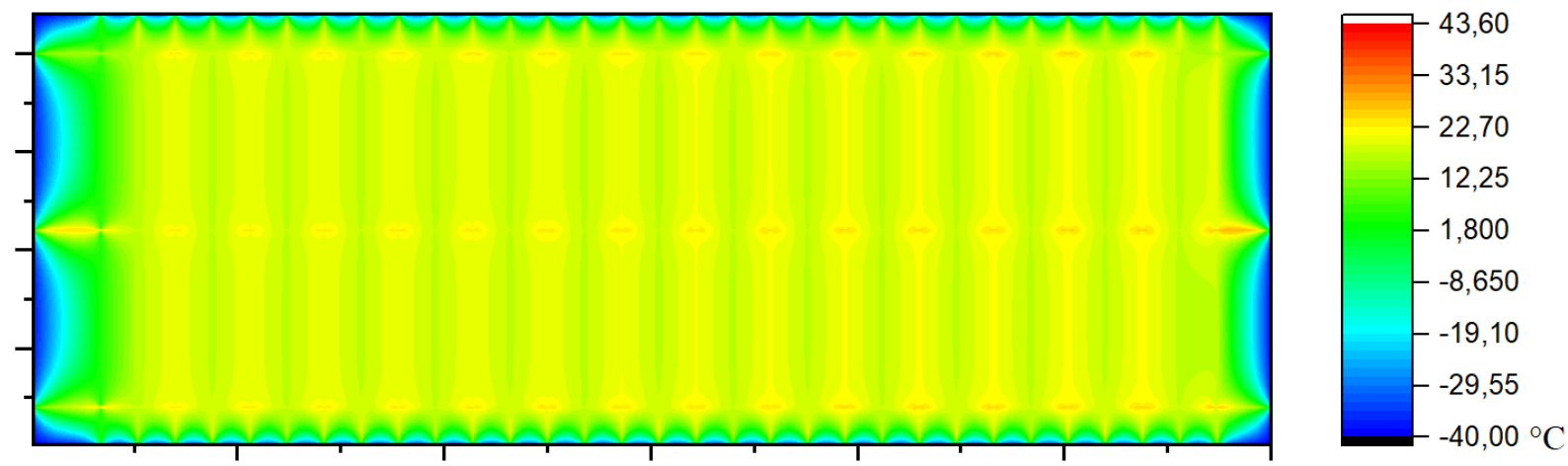

Figure 5: Temperature map. Second version panel

The maximum temperature on the surface of the panel was up to $27.5{ }^{\circ} \mathrm{C}$, which is also unacceptable for comfort requirements, but is observed only in some few areas of the floor.

This modification of the panel allows to practically observe comfortable conditions, however, the closer the heating system pipes are to the outer surface, the more heat flow will go through the outer surface of the floor.

Therefore, the third option of panel modification is to use the first panel design, but with a decrease in the temperature of the coolant at the entrance to the panel from $95{ }^{\circ} \mathrm{C}$ to $70{ }^{\circ} \mathrm{C}$ [10]. The calculation results are shown in figure 6.
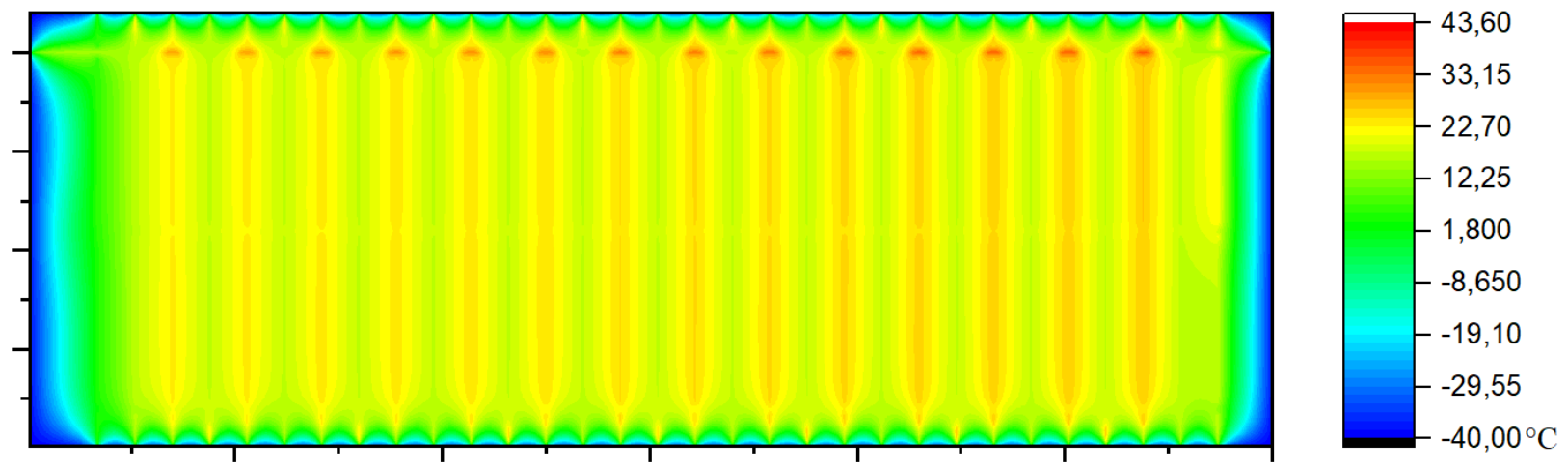

Figure 6: Temperature map. Third version panel

The maximum temperature on the panel surface was $35.8{ }^{\circ} \mathrm{C}$, which is also unacceptable for comfort conditions

\section{RESULTS OF THE CALCULATION}

As a result of calculations, several variants of models for laying the heating system in the barrier structure are obtained, and variants of the influence of the thermal field for different configurations are presented visually.

\section{CONCLUSION}

The following tasks possessing a theoretical significance have been performed in this work:

1) Several variants of the mathematical model of the heating system for residential capsules intended for operation in the far North are proposed.

2) The distribution of heat on the inner surface of the enclosing structure is presented.

3) Several options for laying and using heating systems in the barrier structure are proposed
Based on the developed model, it is possible to conduct research not only on the proposed design with the use of a water heating system, but also, for example, when laying heat-generating electric cables. Based on the model, it is possible to determine the optimal design and temperature conditions of the panel itself, as well as the ability to determine the heat loss of the enclosing structures of the modules.

\section{REFERENCES}

1. S.A. Slavgorodsky, Prospects for the use of sea containers in construction when creating infrastructure in the far North. In the collection: North of Russia: strategies and prospects of development materials of the II all-Russian scientific and practical conference, 2016, pp. 113-121.

2. D.A. Golenkov, T.S. Karpova, The Advantage of modular construction in permafrost and seismic activity zones. In the collection: Materials of the 59th student scientific and technical conference of the 
V.D. Makarishev et al., International Journal of Emerging Trends in Engineering Research, 8(4), April 2020, 1217 - 1221

engineering and construction, Institute of TOGU, 2019, pp. 354-358.

3. Yu.G. Granik, I.A. Braunsdorf, High-speed construction of low buildings of collapsible block containers, Building material, 4, 2005, pp. 17-20.

4. N.I. Dokunikhin, Economic efficiency of innovative production of mobile buildings, Economic and social changes: facts, trends, forecast, vol. 2, no. 10, 2010, pp. 82-87.

5. A.V. Lukov, The use of modular buildings in construction, Innovation and investment, no. 7, 2017, pp. 100-118.

6. A.N. Ishkov, N.A. Malova, V.O. Maltsev, A.E. Chursin, Organization of comfortable selective collection of solid waste in residential buildings, Housing and communal infrastructure, vol. 2, no. 5, 2018, pp. 18-25.

7. V.V. Pyrkov. Gidravlicheskoe regulirovanie sistem otopleniya i okhlazhdeniya: teoriya i praktika [Hydraulic adjustment of heating and cooling systems, Theory and practice]. Kiev: Taki spravi, 2010.

8. N.N. Rudenko, I.V. Bondarev. Choice of boundary conditions for modeling of the soil temperature field, Don engineering Bulletin, no. 4, 2013.

9. E.G. Malyavina, O.D. Samarin. Stroitel'naya teplofizika i mikroklimat zdanii [Thermal physics for construction and building microclimate]: Guidebook. Moscow: MISI-MGSU, EBS ASV, 2018.

10. I.N. Fursova, Yu.A. Tereznikov, Influence of the coolant temperature on the distribution of the surface temperature of the Underfloor heating, Materials of the International scientific and practical conference "Construction 2013". Rostov-on-don: RSSU, 2013, p. 81. 